\title{
Unusual Reversal of Enantioselectivity in the Proline-Mediated $\alpha$-Amination of Aldehydes Induced by Tertiary Amine Additives
}

\author{
Donna G. Blackmond, ${ }^{1,2, \star \ddagger}$ Antonio Moran, ${ }^{1}$ Matthew Hughes, ${ }^{1}$ Alan Armstrong, ${ }^{1 *}$ \\ ${ }^{1}$ Department of Chemistry and ${ }^{2}$ Department of Chemical Engineering, Imperial College London SW7 2AZ, UK \\ RECEIVED DATE (automatically inserted by publisher); a.armstrong@imperial.ac.uk. blackmond@scripps.edu
}

The renaissance in organocatalysis that was sparked by the List, Lerner, and Barbas ${ }^{1}$ study of the proline-mediated aldol reaction has led to reports of a wide variety of electrophile/ nucleophile reactions catalyzed by a range of primary and secondary amines. ${ }^{2}$ In addition to its efficiency in the archetypal aldol reaction, proline has also been shown to be effective in other enantioselective transformations thought to proceed via an enamine mechanism, including Mannich reactions, enamine addition to azo and nitroso groups, and conjugate addition to a number of different Michael acceptors.

Additives such as water, acids, and bases have been shown to influence either or both reactivity and enantioselectivity in transformations catalyzed by amine-based catalysts. ${ }^{3}$ Our recent studies suggest that the rate of proline enamine formation is enhanced in the presence of protic additives, without affecting product enantioselectivity, in the aminoxylation and $\alpha$-amination of propionaldehyde (Scheme 1). ${ }^{3 \mathrm{~g}}$ We report here that addition of organic bases in the $\alpha$-amination of aliphatic aldehydes results in an intriguing reversal of product enantioselectivity as well as changes in the kinetic profile. The mechanistic implications of these findings are discussed in the context of contending models for the enantiodifferentiating step in enamine catalysis.

Scheme 1. Proline-catalyzed $\alpha$-amination of propionaldehyde.<smiles>CCOC(=O)N=[NH+]CC=O</smiles>

1a

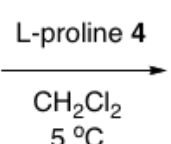<smiles>CCOC(=O)NN(C(=O)OCC)[C@@H](C)C=O</smiles>

3a
Figure 1 compares reaction rate as a function of fraction conversion in the $\alpha$-amination of propionaldehyde with DEAD (Scheme 1) using fully solubilized proline ${ }^{4}$ as catalyst both in the absence and presence of catalytic amounts of the organic base DBU. The kinetic profile is altered from the sigmoidal shape characteristic of this reaction to reveal initially positive order kinetics followed by a zero order regime. Strikingly, the presence of DBU induces a reversal of product enantioselectivity from $85 \%$ $(R)$ to $46 \%(S)$. A similar reversal of enantioselectivity was observed with other tertiary amines, correlating roughly with $\mathrm{pK}_{\mathrm{a}}$ as shown in Figure 2. Interestingly, phosphazene bases of even higher $\mathrm{pK}_{\mathrm{a}}$ gave product ee values similar to $\mathrm{DBU}\left(\mathrm{P}_{1^{-}}{ }^{t} \mathrm{Bu}, 58 \%\right.$ ee; $\mathrm{P}_{2}{ }^{t} \mathrm{Bu}, 56 \%$ ee; BEMP, $57 \%$ ee). The strongest (and bulkiest) base tested, $\mathrm{P}_{4}{ }^{-} \mathrm{Bu}$, gave none of the reaction product $\mathbf{3 a}$.

Table 1 shows that this reversal of enantioselectivity holds for a range of aliphatic aldehydes (compare entries 7-12 to 1-6). The reaction product was stable to racemization when [DBU] did not exceed [4], although racemization is observed when DBU is mixed with the product in the absence of proline. ${ }^{4}$ Product enantioselectivity in the presence of DBU was highest when the
DBU: proline [4] ratio was ca. 0.9:1, while lower DBU concentrations gave the same trend but a less pronounced reversal of enantioselectivity.

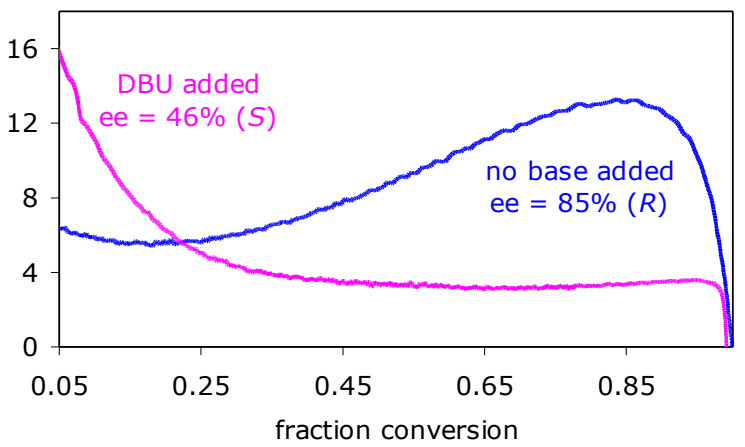

Figure 1. Reaction of Scheme 1 carried out in $\mathrm{CH}_{2} \mathrm{Cl}_{2}$ at $5{ }^{\circ} \mathrm{C}$ in the absence and presence of added DBU (0.9 equivalents compared to proline). $[1]_{0}=2.2 \mathrm{M} ;[2]_{0}=0.7 \mathrm{M} ;[4]=0.03 \mathrm{M}$.

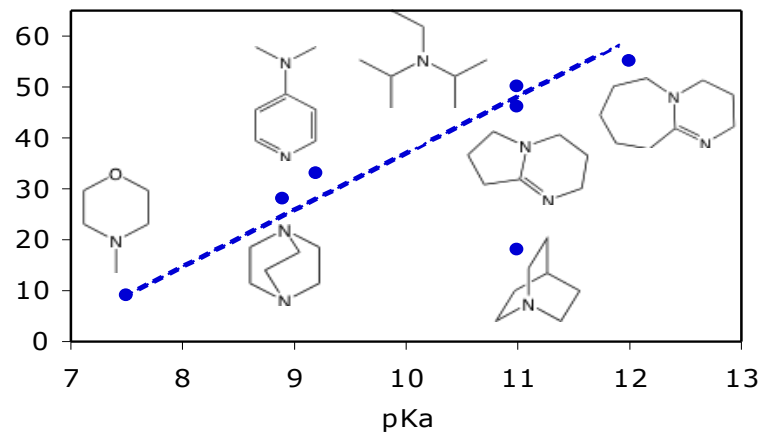

Figure 2. Product ee $(S)$ in the reaction of Scheme 1 in the presence of tertiary amine additives of different aqueous $\mathrm{pK}_{\mathrm{a}}$ values $(0.9$ equivalents compared to proline). ${ }^{4}$

Addition of bases in enamine catalysis has not been been extensively studied, ${ }^{3 \mathrm{a}, 3 \mathrm{~h}}$ and to our knowledge an inversion of ee in the presence of base such as we observe here has not been reported previously. ${ }^{5}$ The most significant conceptual role proposed for base additives comes from the work of Seebach and Eschenmoser, ${ }^{6}$ whose studies of preformed oxazolidinones in stoichiometric interactions with bases such as DBU led to their proposal that the enamine carboxylate is a key reaction intermediate. In order to rationalize the observed $R$-selectivity in the proline-catalyzed reaction, they suggested anti-addition to the syn-enamine rotamer (Scheme 2, TS-B), which leads directly to the more stable, exo-isomer of the product oxazolidinone. This is in contrast to the Houk-List model, ${ }^{7}$ which has been widely adopted to account for stereocontrol in proline-mediated alpha- 
functionalization reactions, and centers on the key role of the carboxylic acid proton in directing the electrophile to the $R e$-face of the anti-enamine rotamer (Scheme 2, TS-A). The reversal of selectivity that we have observed in the presence of base can be explained by assuming that TS-B is less favorable than the alternative TS-C, which involves approach of the electrophile on the anti-enamine rotamer on the opposite face to the carboxylate. The carboxylate could act either as a steric blocking group (analogous to the Jørgensen/Hayashi diaryl prolinol catalysts, ${ }^{8,9}$ which also afford product selectivity opposite to that of proline in the amination reaction ${ }^{8}$ ), or - in line with the SeebachEschenmoser idea - it may participate in the addition step. In this scenario, as pointed out by Seebach and Eschenmoser, TS-C is likely to be stereoelectronically more favorable than TS-B, but leads to the less stable, endo-oxazolidinone of the product. Competition between TS-A and TS-C would be expected to be influenced by the basicity of the additive, accounting for the observed trend in enantioselectivity.

Table 1. Organocatalytic amination of aldehydes. ${ }^{a}$<smiles>[R2]OC(=O)N=N[C@H]([R])C=O</smiles>
\begin{tabular}{l} 
1) Catalyst \\
(20 $\left.\mathrm{mol}_{0}\right)$ \\
2) $\mathrm{NaBH}_{4}$ \\
\hline 3) $0.5 \mathrm{~N} \mathrm{NaOH}$
\end{tabular}<smiles>[R]OC(=O)NN1C(=O)OCC1[R]</smiles>

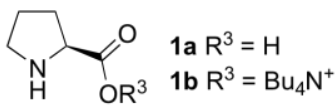<smiles>c1nnc(C2CCCN2)[nH]1</smiles>

\begin{tabular}{|c|c|c|c|c|c|c|}
\hline Entry & $\mathrm{R}^{1}$ & $\mathrm{R}^{2}$ & Catalyst & $\%$ Yield $^{b}$ & $\% \mathrm{ee}^{c}$ & config \\
\hline 1 & $\mathrm{Me}$ & $\mathrm{Et}$ & $1 a$ & 67 & 85 & $R$ \\
\hline 2 & $\mathrm{Me}$ & $\mathrm{Bn}$ & $1 \mathrm{a}$ & 68 & $85^{d}$ & $R$ \\
\hline 3 & $i$-Pr & $\mathrm{Et}$ & $1 a$ & 73 & 93 & $R$ \\
\hline 4 & $t-\mathrm{Bu}$ & $\mathrm{Et}$ & $1 a$ & 50 & 85 & $R$ \\
\hline 5 & allyl & $\mathrm{Et}$ & $1 \mathrm{a}$ & 82 & 88 & $R$ \\
\hline 6 & $\mathrm{Bn}$ & Et & $1 a$ & 68 & $88^{e}$ & $R$ \\
\hline 7 & $\mathrm{Me}$ & $\mathrm{Et}$ & $\mathbf{1 a} / \mathrm{DBU}^{f}$ & 60 & 46 & $S$ \\
\hline 8 & $\mathrm{Me}$ & $\mathrm{Bn}$ & $\mathbf{1 a} / \mathrm{DBU}^{f}$ & 61 & $52^{d}$ & $S$ \\
\hline 9 & $i$-Pr & $\mathrm{Et}$ & $\mathbf{1 a} / \mathrm{DBU}^{f}$ & 64 & 55 & $S$ \\
\hline 10 & $t-\mathrm{Bu}$ & $\mathrm{Et}$ & $\mathbf{1 a} / \mathrm{DBU}^{f}$ & 35 & 44 & $S$ \\
\hline 11 & allyl & $\mathrm{Et}$ & $\mathbf{1 a} / \mathrm{DBU}^{f}$ & 74 & 54 & $S$ \\
\hline 12 & $\mathrm{Bn}$ & $\mathrm{Et}$ & $\mathbf{1 a} / \mathrm{DBU}^{f}$ & 60 & $25^{e}$ & $S$ \\
\hline $13^{\mathrm{g}}$ & $\mathrm{Me}$ & $\mathrm{Et}$ & $1 b$ & 16 & 60 & $S$ \\
\hline $14^{h}$ & $\mathrm{Me}$ & $\mathrm{Et}$ & 1c & 62 & 84 & $R$ \\
\hline $15^{h}$ & $\mathrm{Me}$ & Et & 1c/DBU ${ }^{f}$ & 59 & 46 & $S$ \\
\hline
\end{tabular}

${ }^{a}$ The reaction of the aldehyde $(1.5 \mathrm{mmol})$ with azodicarboxylate $(0.5 \mathrm{mmol})$ in $2.5 \mathrm{ml}$ of $\mathrm{CH}_{2} \mathrm{Cl}_{2}$ at $0{ }^{\circ} \mathrm{C}$. ${ }^{b}$ Isolated yields. ${ }^{c}$ Determined by $\mathrm{GC}$ using a chiral Chrompack CP Chiralsil-Dex C $\beta$ Column. ${ }^{d}$ Determined by HPLC on alcohol produced from $\mathrm{NaBH}_{4}$ reduction using a Chiralpak OD column. ${ }^{e}$ Determined by HPLC using a Chiralpak AD column. ${ }^{f} 0.9$ DBU/catalyst ratio used. ${ }^{g}$ low yield due to consumption of DEAD in side reactions. ${ }^{h}$ Reaction at room temperature.

Based on the hypothesis that the inversion of enantioselectivity in the presence of basic additives might be attributed to an enamine carboxylate intermediate, we next investigated the efficacy of preformed prolinate salts as catalysts for the reaction of Scheme 1. Such compounds have been employed in Michael and intramolecular aldol reactions ${ }^{10}$ but not to our knowledge in the $\alpha$-amination. We found that prolinate salts with tetraalkylammonium counter cations catalyze the reaction with selectivity in the same sense as the DBU-proline system (Table 1, entry 13). The tetrabutylammonium system gave the highest inversion, $60 \%$ ee $(S)$, which is comparable to the highest ee observed with tertiary nitrogen bases. Prolinate salts of Group 1 metals showed no selectivity, although reactivity appears to be comparable to proline-catalyzed reactions. ${ }^{4}$ Interestingly, the reversal of product enantioselectivity was also observed using the proline tetrazole derivative 1c (entries 14-15), demonstrating that the effect is not limited simply to proline.

Scheme 2. Mechanistic models for enantiodifferentiation in proline catalysis between a carbonyl compound and an electrophile $\mathrm{X}=\mathrm{Y}$.

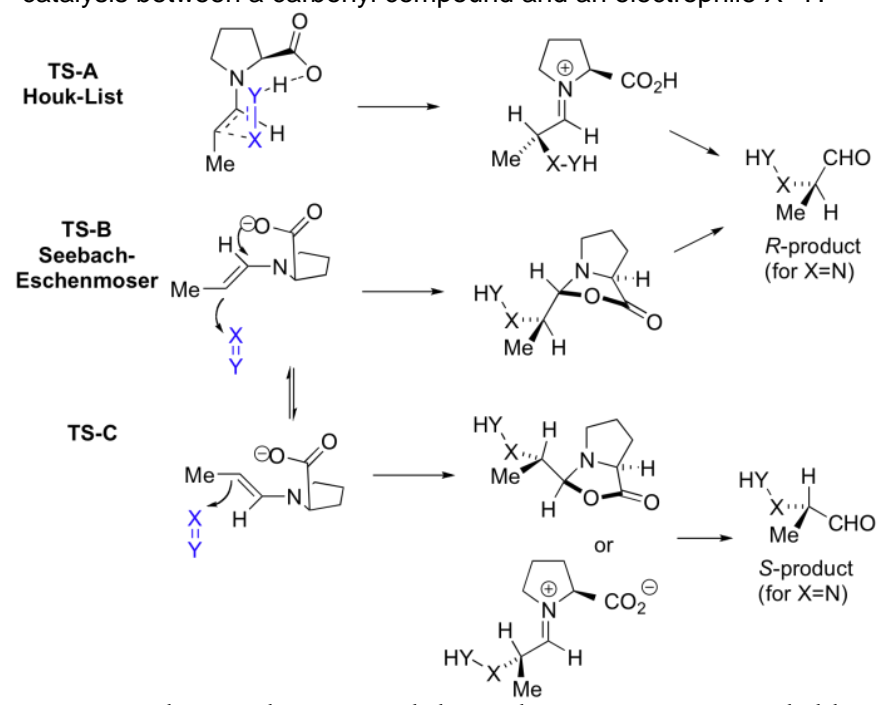

The results reported here demonstrate a remarkable inversion of enantioselectivity in a proline-catalyzed reaction by an experimentally simple modification, addition of catalytic amounts of organic base. These observations have important implications for the stereochemical models for proline and related aminocatalytic transformations as well as for their practical application. Wider exploitation of the concept and further computational and mechanistic studies are underway.

Acknowledgment. We acknowledge EPSRC funding (AA/DGB), a Royal Society Wolfson Research Merit Award (DGB), and a Fundacion Ramón Areces (Spain) fellowship (AM).

Supporting Information. Details of experimental procedures (46 pages).

$\$$ Present address: Department of Chemistry, The Scripps Research Institute, La Jolla, CA 92037 USA.

1 List, B.; Lerner, R. A.; Barbas, C. F. J. Am. Chem. Soc. 2000, 122, 2395

2 a) Mukherjee, S.; Yang, J. W.; Hoffmann, S.; List, B. Chem. Rev. 2007, 107, 5471; b) Melchiorre, P.; Marigo, M.; Carlone, A.; Bartoli, G. Angew. Chem Int. Ed. 2008, 47, 6138; c) Bertelsen, S.; Jørgensen, K. A. Chem. Soc. Rev. 2009, 38, 2178 .

3 a) Pihko, P. M.; Laurikainen, K. M.; Usano, A.; Nyberg, A. I.; Kaavi, J. A Tetrahedron 2006, 62, 317; b) Zotova, N.; Franzke, A.; Armstrong, A.; Blackmond, D. G. J. Am. Chem. Soc. 2007, 129, 15100; c) Zotova, N.; Broadbelt, L. J.; Armstrong, A.; Blackmond, D. G. Bioorg. Med. Chem. Lett. 2009, 19, 3934; d) Gu, Q.; Wang, X. F.; Wang, L.; Wu, X. Y.; Zhou, Q. L. Tetrahedron: Asymmetry 2006, 17, 1537; e) Guizzetti, S.; Benaglia, M.; Raimondi, L.; Celentano, G. Org. Lett. 2007, 9, 1247; f) Ma, G. N.; Zhang, Y. P.; Shi, M. Synthesis 2007, 197; g) Zotova, N.; Moran, A.; Armstrong, A.; Blackmond, D. G. Adv. Synth. Catal. 2009, 351, 2765; h)Amedjhouh, M., Tetr. Asymm., 2007, 18, 390 .

4 See Supporting Information

5 Bartock, M. Chem. Rev., 2010, 110, 1663.

6 Seebach, D.; Beck, A. K.; Badine, D. M.; Limbach, M.; Eschenmoser, A.; Treasurywala, A. M.; Hobi, R.; Prikoszovich, W.; Linder, B. Helv. Chim. Acta $\mathbf{2 0 0 7}, 90,425$.

7 a) Bahmanyar, S.; Houk, K. N. J. Am. Chem. Soc. 2001, 123, 11273; b) Bahmanyar, S.; Houk, K. N.; Martin, H. J.; List, B. J. Am. Chem. Soc 2003, 125, 2475; c) Cheong, P. H. Y.; Houk, K. N. Synthesis 2005, 1533 ; d) Hoang, L.; Bahmanyar, S.; Houk, K. N.; List, B. J. Am. Chem. Soc. 2003, 125, 16; e) List, B.; Hoang, L.; Martin, H. J. Proc. Natl. Acad. Sci. U. S. A. 2004, 101, 5839; f) Clemente, F. R.; Houk, K. N. Angew. Chem., Int. Ed. 2004, 43, 5766.

8 Franzen, J.; Marigo, M.; Fielenbach, D.; Wabnitz, T. C.; Kjærsgaard, A.; Jørgensen, K. A. J. Am. Chem. Soc. 2005, 127, 18296.

9 Hayashi, Y. Angew. Chem., Int. Ed. 2006, 45, 8103.

10 a) Yamaguchi, M.; Shiraishi, T.; Hirama, M. J. Org. Chem. 1996, 61, 3520; Yamaguchi, M.; Igarashi, Y.; Reddy, R. S.; Shiraishi, T.; Hirama, M. Tetrahedron 1997, 53, 11223 . 


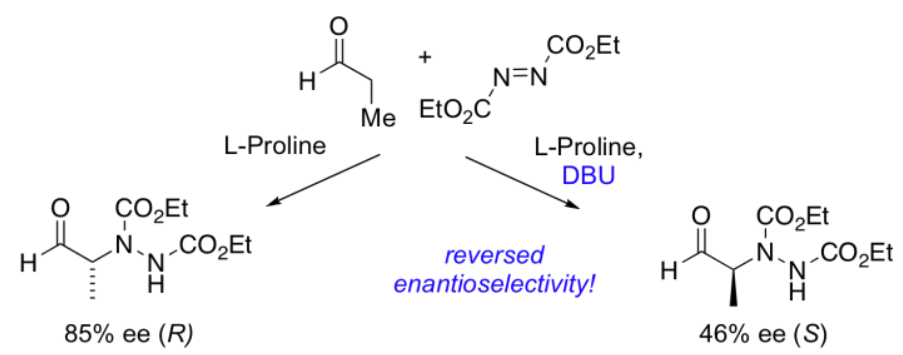

An intriguing reversal in product enantioselectivity accompanied by a change in the kinetic profile is observed in the $\alpha$ amination of aldehydes catalyzed by proline in the presence of organic bases. Implications for the prevailing stereochemical models for proline and related aminocatalytic transformations are discussed. 